\title{
Wilms' Tumor Gene 1 (WT1) Peptide Vaccine Therapy for Hematological Malignancies: From CTL Epitope Identification to Recent Progress in Clinical Studies Including a Cure-Oriented Strategy
}

\author{
Yoshihiro Oka ${ }^{a, b, c} \quad$ Akihiro Tsuboi $^{d}$ Jun Nakata $^{d}$ Sumiyuki Nishidab Naoki Hosen $^{a}$ \\ Atsushi Kumanogoh ${ }^{b, c}$ Yusuke Ojie Haruo Sugiyama ${ }^{f}$ \\ a Department of Cancer Stem Cell Biology, Osaka University Graduate School of Medicine, Suita, Japan; \\ ${ }^{b}$ Department of Respiratory Medicine and Clinical Immunology, Osaka University Graduate School of Medicine, Suita, Japan; \\ ${ }^{c}$ Department of Immunopathology, WPI Immunology Frontier Research Center, Osaka University, Suita, Japan; \\ dDepartment of Cancer Immunotherapy, Osaka University Graduate School of Medicine, Suita, Japan; \\ e Department of Functional Diagnostic Science, Osaka University Graduate School of Medicine, Suita, Japan; \\ f Department of Cancer Immunology, Osaka University Graduate School of Medicine, Suita, Japan
}

\section{Keywords}

Wilms' tumor gene 1 . WT1 . Peptide vaccine .

Immunotherapy · Leukemia · MDS

\section{Summary}

The identification of human Wilms' tumor gene 1 (WT1) protein-derived cytotoxic T lymphocyte (CTL) epitopes and the in vivo efficacy of WT1 peptide-based immunotherapy in a mouse model were reported in 2000 . This successful basic research led to clinical studies of a WT1 peptide vaccine, and a positive impact on clinical response was first demonstrated in 2003 in the form of a reduction in blast cells of vaccine-treated patients with myelodysplastic syndromes (MDS). Since then, data on WT1 peptide vaccine-treated patients with immunological and/or clinical response have been accumulated. MDS and acute myeloid leukemia were the major target diseases to provide proof of concept for the therapeutic potential of the WT1 peptide vaccine. WT1 vaccinationinduced clinical responses or usefulness were also shown for chronic myeloid leukemia, multiple myeloma, and acute lymphoblastic leukemia, as well as various types of solid cancers. Non-Hodgkin's lymphoma and myeloproliferative neoplasms may also be target diseases because of their WT1 expression. Of note, recent clinical studies have demonstrated that patients with hematological malignancies who have minimal residual disease after chemotherapy or allogeneic hematopoietic stem cell transplantation may be cured by WT1 peptide vaccination. Further enhancement of the efficacy and usefulness of the WT1 peptide vaccine is expected.

(c) 2017 S. Karger GmbH, Freiburg

\section{Introduction}

Wilms' tumor gene (WT1) is expressed in various types of hematological malignancies and solid cancers [1]. The WT1 expression level in peripheral blood (PB) is currently used as a minimal residual disease (MRD) marker in acute myeloid leukemia (AML) or myelodysplastic syndromes (MDS) $[2,3]$. In addition, WT1 plays oncogenic roles in various types of malignant tumors, which indicates that tumor escape as a result of down-regulation of the antigen is unlikely to occur in WT1-targeting immunotherapy [4]. These findings suggest that WT1 is a prime target antigen for cancer immunotherapy $[1,4,5]$. In fact, WT1 was rated the most promising among the 75 representative target antigens [5]. Other features of WT1 demonstrated in recent investigations, such as WT1 expression in AML stem cells or tumor vessels that provide tumor cells with nutrition, also should be advantageous to its use as a target antigen of immunotherapy $[6,7]$.

\section{KARGER}

(c) 2017 S. Karger GmbH, Freiburg 
In this review, we summarize the developments and recent advancements of WT1-targeting immunotherapy with a focus on WT1 peptide vaccination for hematological malignancies.

\section{Identification of WT1 CTL Epitopes as Direct Proof that WT1 is a Potential Target Antigen for Cancer Immunotherapy}

In 2000, Oka et al. [8] and Ohminami et al. [9] reported the identification of the human WT1 peptides WT1-126 and WT1235 (arbitrary nomenclature based on the N-terminus amino acid of each 9-mer peptide) that could induce WT1-specific cytotoxic T lymphocytes (CTLs) in vitro in the restriction of HLA- $A^{\star} 0201$ and HLA-A ${ }^{\star} 2402$, respectively, which are HLA class I types frequently found in humans. The authors showed the possibility that vaccination of cancer patients with HLA-A 0201 or HLA-A ${ }^{\star} 2402$ by each HLA type-restricted WT1 peptide could induce CTLs that attack WT1-expressing tumor cells by a mechanism described and illustrated elsewhere [10]. Gao et al. [11], in 2000, using an allo-restricted CTL approach that is independent of immunologic tolerance, also reported the identification of a HLA-A ${ }^{\star} 0201$-restricted WT1 CTL peptide, which was identical to the WT1-126 peptide Oka et al. [8] identified. It was also reported by Oka et al. [12] in 2000 that in vivo vaccination of mice with WT1 peptide induced WT1-specific CTLs, leading to tumor rejection, which strongly suggested that WT1 can serve as a target antigen for immunotherapy in vivo. These findings reported in 2000 indicated that WT1 is a potential target antigen for cancer immunotherapy, and constituted the very beginning of the development of WT1-targeting cancer immunotherapy.

This was followed by a series of investigations reporting the identification of other WT1 CTL peptides, including modified ones that can induce WT1-specific CTLs more vigorously than the original, WT1 helper peptides that can induce WT1-specific helper $\mathrm{CD}^{+} \mathrm{T}$ cells, and long peptides that contain both CTL and helper epitopes $[4,13]$.

\section{Clinical Studies of WT1 Peptide Vaccine in the 'Early Phase' to Establish Proof of Concept for the Therapeutic Potential}

First Case Reports Showing Positive Impact on Clinical Response

In order to examine whether WT1-targeting immunotherapy, including a WT1 peptide vaccine, has therapeutic potential, it is essential to perform a clinical study of this immunotherapy alone without any other treatment. The first cases treated with the WT1 peptide vaccine that showed clinical responses were reported by Oka et al. [14] in 2003. The cases were 2 HLA-A ${ }^{\star 2402-p o s i t i v e ~ p a-~}$ tients with MDS-related diseases. A HLA-A ${ }^{\star} 2402$-restricted modified WT1 peptide (WT1-235m) emulsified with Montanide immune adjuvant was intradermally (i.d.) injected, which induced a reduction in the percentage of blast cells in the bone marrow (BM) or WT1 mRNA levels in BM or PB. An increase in the frequencies of WT1-specific CTLs in PB after the vaccination, detected by WT1 tetramers, was observed in 1 of the 2 patients.

As for patients with HLA-A $A^{\star} 201$, another frequently found HLA class I type, a case report by Mailänder et al. [15] in 2004 provided first data. The i.d. and subcutaneous (s.c.) vaccination of the patient with WT1-126 admixed with keyhole limpet hemocyanin $(\mathrm{KLH})$, in combination with the s.c. injection of granulocyte-macrophage colony-stimulating factor (GM-CSF), induced a reduction in blast cells, followed by a durable complete remission (CR). An increase in the frequency of WT1-specific CTLs in PB after the vaccination was also observed.

Clinical studies of WT1 peptide vaccine therapy with a clinically positive impact, including these first case reports, are listed in the supplementary table (www.karger.com/?DOI=481353).

\section{Proof of Concept for the Therapeutic Potential of the WT1 \\ Peptide Vaccine}

Following the first case reports of WT1 peptide vaccine therapy, a series of successful WT1 peptide vaccine clinical studies with relatively small numbers of patients were reported, which demonstrated the therapeutic potential of the vaccine, leading to establishment of proof of concept for the vaccine's potency. AML and MDS were the major target diseases in these early clinical studies.

In 2004, Oka et al. [16] reported WT1 peptide vaccination-induced WT1-specific immunological responses and resultant clinical responses in HLA-A ${ }^{\star} 2402$-positive patients with AML, MDS-related diseases, breast cancer, and lung cancer. The patients were i.d. vaccinated with Montanide-emulsified WT1 peptide, and their immunological and/or clinical responses, including a reduction in the blast percentage in BM of AML patients, were observed. The most important finding in this study was that of a correlation between the induction of WT1-specific immunological responses, i.e., an increase in the frequency of WT1-specific CTLs, and the occurrence of clinical responses. This finding strongly suggested that the WT1 peptide vaccine has the potential to induce WT1-specific immunological responses which lead to the occurrence of clinical responses.

In 2008, Revzani et al. [17] also reported an association between an increase in WT1-specific CTLs in PB and a decrease in MRD in patients with MDS or AML, in which HLA-A*0201-positive patients were s.c. vaccinated with WT1-126 peptide and proteinase 3-derived PR1 peptide emulsified with Montanide, in combination with the s.c. injection of GM-CSF. This finding also provided proof of concept for the therapeutic potential of the WT1 peptide vaccine. Subsequently, Keilholz et al. [18] reported in 2009 the results of a phase II study of WT1 peptide vaccine therapy in patients with AML and MDS, in which HLA-A ${ }^{\star} 0201$-positive patients were i.d. and s.c. vaccinated with WT1-126 peptide admixed with KLH, in combination with the s.c. injection of GM-CSF. In this study, too, clinical responses, such as a reduction in blast cells or WT1 mRNA levels and hematological improvement, were observed.

Taken together, from the results of the above early clinical studies, it appeared certain that the WT1 peptide vaccine had therapeu- 
tic potential, although the peptide dose, vaccination route (i.d. or s.c.), and immune adjuvant differed among the 3 studies. Other clinical studies of WT1 peptide vaccine therapy targeting myeloid malignancies also showed positive and interesting results $[19,20]$, thus providing further evidence for its therapeutic potential.

A clinical study reported by Van Tendeloo et al. [21] in 2010 provided solid evidence for the therapeutic potential of WT1-targeting immunotherapy, although the treatment did not use WT1 peptide but WT1 mRNA-electroporated dendritic cells. They reported that the i.d. vaccination of AML patients succeeded in inducing a CR from partial remission, and normalization of an AML-associated tumor marker after the vaccination, i.e., an induction of molecular remission [21]. Immunological responses, including an increase in WT1-specific $\mathrm{CD} 8^{+} \mathrm{T}$ cell frequencies, were also detected after the vaccination.

Besides hematological malignancies such as AML and MDS, WT1 vaccination-induced immunological and/or clinical responses were reported for various types of solid cancers $[1,4]$.

\section{Potential Target Hematological Malignancies other than AML and MDS}

As described above, the therapeutic potential of the WT1 peptide vaccine in hematological malignancies was mainly demonstrated for AML and MDS.

As for other diseases, Tsuboi et al. [22] reported in 2007 that WT1 peptide vaccination induced a clinical response in a patient with advanced-stage multiple myeloma. The HLA-A ${ }^{\star} 2402$-positive patient was i.d. vaccinated with Montanide-emulsified WT1-235m peptide, which induced a WT1-specific immunological response, as well as clinical responses, including a reduction in myeloma cells in $\mathrm{BM}$ and a reduction in $\mathrm{M}$-protein.

Chronic myelogenous leukemia (CML) is another candidate target disease. Narita et al. [23] and Oji et al. [24] reported clinical responses in patients with CML in 2010. The CML patients were being treated with imatinib, a tyrosine kinase inhibitor (TKI), but still showed MRD detected by measuring $b c r-a b l$ mRNA in PB. The patients were HLA-A ${ }^{\star} 2402$-positive, and vaccine therapy with WT1 $-235 \mathrm{~m}$ peptide emulsified with Montanide was added (s.c. in Narita et al.'s [23] and i.d. in Oji et al.'s [24] study) without cessation of imatinib. After the vaccination, WT1-specific immunological responses and a decrease in bcr-abl mRNA levels were observed, which suggested the usefulness of a combined therapy of WT1 peptide vaccine and TKI.

As is described later in more detail, patients with acute lymphoblastic leukemia (ALL) in CR but with a high risk of relapse after allogeneic hematopoietic stem cell transplantation (allo-HSCT) showed long-term maintenance of CR when treated with the WT1 peptide vaccine, which strongly suggests that ALL also constitutes a target disease for this vaccine therapy [25-27].

Israyelyan et al. [28] reported that a large percentage of patients with non-Hodgkin's lymphoma (NHL) maintained WT1-specific $\mathrm{T}$ cells and that WT1 mRNA transcripts were detected in diseased lymph node tissues of many of NHL patients, which suggests that NHL could also be a target disease. In addition, myeloproliferative neoplasms may qualify as a target because of the inherent WT1 expression [29]. The list of target diseases may further increase in the future.

\section{Clinical Studies of WT1 Peptide Vaccine in the 'Advanced Phase' Aiming to Establish a Cure- Oriented Strategy}

After the accumulation of evidence of the therapeutic potential of the WT1 peptide vaccine in the 'early phase' studies, a series of studies of the vaccine as a post-remission therapy aiming to lead the patients to a cure were performed. In 2010, Maslak et al. [30] reported the results of WT1 peptide vaccine therapy for AML patients, including those with HLA-A ${ }^{\star} 0201$, in CR but with molecular evidence of MRD. They used a modified WT1-126 peptide (WT1-126m), WT1 helper peptides, and a helper peptide that also included a CTL epitope (WT1-126m), which were emulsified with Montanide. WT1-specific T cell responses were detected, and the clinical outcome such as disease free-survival might be promising.

As an extension of the phase I study reported by Oka et al. [16] in 2004, Tsuboi et al. [31] reported in 2012 that 3 out of 8 HLA-A ${ }^{\star} 2402$-positive AML patients showed long-term survival of more than 7 years with only the continuation of i.d. vaccination of WT1-235m peptide emulsified with Montanide. These 3 patients all had MRD before the vaccination and were thought to be destined to relapse. WT1 mRNA levels, an MRD marker, showed a gradual decrease with some fluctuations during the vaccination period, followed by the attainment of a sustained molecular CR, which suggested a cure.

In the setting of post-allo-HSCT, in which most patients have only MRD, Hashii et al. [25] performed i.d. vaccination of WT1$235 \mathrm{~m}$ emulsified with Montanide for HLA-A ${ }^{\star} 2402$-positive pediatric patients with acute leukemia who had received allo-HSCT but were at high risk of relapse. In this study reported in 2012, longlasting remission was attained in 2 (ALL and AML) of the 3 patients. Since allo-HSCT is a kind of immunotherapy targeting alloantigens, the WT1 peptide vaccination after allo-HSCT constitutes a combination treatment comprising 2 different immunotherapies. Consistent with this result, Sawada et al. [26] also reported that a pediatric patient with ALL, who was in CR but at high risk of relapse after allo-HSCT and was treated with the vaccine, showed long-lasting CR. In 2013, Maeda et al. [27] reported promising results for the WT1 peptide vaccination after allo-HSCT for the prevention of relapse of AML and ALL, in which HLA-A ${ }^{\star} 2402$-positive adult patients were treated by i.d. injection of WT1-235m emulsified with Montanide.

Very recently, Nakata et al. [32] also reported a favorable result with the WT1 peptide vaccine in the context of a cure-oriented strategy. HLA-A ${ }^{\star} 0201$ or HLA-A ${ }^{\star} 2402$-positive AML patients in CR but at high risk of relapse after chemotherapy, including those with MRD at the molecular level, were i.d. vaccinated with Montanide- 
Table 1. Possible strategies for maximizing the effect of the WT1 peptide vaccine

1. Choice of clinical settings appropriate for vaccine use

Vaccination of patients in CR but with probable existence of MRD

Patients with acute leukemia or MDS in CR but at high risk of relapse after chemotherapy

Patients with acute leukemia or MDS in CR but at high risk of relapse after allo-HSCT ${ }^{\mathrm{a}}$

Vaccination of patients with MDS with normal hematopoiesis and a relatively slow growth rate

2. Improvement of the vaccine composition

Combined use of CTL peptide and helper peptide

Use of long peptide containing CTL epitope and helper epitope

Development of more appropriate adjuvant

3. The vaccine use combined with other treatment

Vaccination of patients with acute leukemia or MDS in CR but at high risk of relapse after allo-HSCT

Vaccination of patients with CML receiving TKI but still having MRD

Vaccine use combined with checkpoint inhibitors ${ }^{\mathrm{b}}$

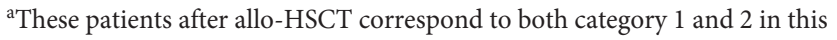
table. See text for detail.

${ }^{\text {b}}$ This strategy is not based on clinical studies published so far. MRD $=$ Minimal residual disease; $\mathrm{MDS}=$ myelodysplastic syndromes; $\mathrm{CR}=$ complete remission; allo-HSCT = allogeneic hematopoietic stem cell transplantation; $\mathrm{CML}=$ chronic myelogenous leukemia; TKI = tyrosine kinase inhibitor;

$\mathrm{CTL}=$ cytotoxic $\mathrm{T}$ lymphocyte

emulsified WT1-126 or WT1-235m, respectively. The 2-year relapse-free survival and 2-year overall survival were approximately 25 and $40 \%$, respectively, which was much better than the estimations made on the basis of the patients' characteristics. Probable prolongation of CR duration in some patients was shown, and, of note, curability of AML patients in CR but at high risk of relapse by treatment with the vaccine was suggested. In this study, WT1 vaccination was started soon after hematopoietic recovery following the completion of chemotherapy, and higher frequencies of WT1-specific CTLs prevaccination were associated with a favorable clinical outcome. Considering that appropriate chemotherapy induces tumor cell death, leading to the induction and promotion of tumor antigen-specific CTLs, the finding of this study suggested the possibility of a synergistic effect of the vaccination and the existing anti-leukemia immunity which seemed to be induced during chemotherapy.

\section{Problems Resulting from Clinical Studies with Negative Outcomes}

In 2001, 2 studies on tumor antigen peptide-based vaccine therapy with negative results were reported.

Revzani et al. [33] reported that the repeated s.c. vaccination with PR1 and WT1 peptides emulsified in Montanide with s.c. GM-CSF injection in patients with myeloid malignancies failed to induce sustained epitope-specific $\mathrm{CD}^{+} \mathrm{T}$ cells with high avidity, although a single dose of the vaccine had induced an increase in epitope-specific $\mathrm{CD} 8^{+} \mathrm{T}$ cells associated with a significant decrease in MRD. Namely, the repeated vaccination led to a loss of peptidespecific $\mathrm{CD}^{+} \mathrm{T}$ cells with high avidity. The authors raised several points that might have unfavorably affected the immunological and clinical outcomes and should be re-evaluated, including the value of GM-CSF as an adjuvant and the possibility of a lack of $\mathrm{CD} 4^{+} \mathrm{T}$ cell-based help.

In the study by Kuball et al. [34], HLA- $A^{\star} 0201$-positive AML patients were s.c. vaccinated with pan HLA-DR helper epitope (PADRE) and either WT1-126 peptide or PR1 peptide with Montanide and CpG7909, while neither obvious clinical responses nor expansion of the antigen-specific $\mathrm{CD} 8^{+} \mathrm{T}$ cells were observed after the vaccination. The authors speculated that the negative impact on the CD8 ${ }^{+} \mathrm{T}$ cells was most likely due to the use of a suboptimal concentration of CpG7909, which may be associated with a suboptimal activation of antigen-presenting cells and a subsequently weakened Th1 response. Although an increase in PADRE-specific $\mathrm{CD}^{+} \mathrm{T}$ cells was observed, these cells appeared to be unable to produce interleukin- 2 . In addition, $\mathrm{CD} 4^{+} \mathrm{T}$ cells with a regulatory phenotype increased.

Taken together, various factors are thought to influence the effect of tumor antigen peptide-based vaccine therapy. Immune adjuvant, application route (i.d. or s.c.), dose, and dosing intervals may be important factors affecting outcome.

\section{Prospects for Enhancing the Efficacy and Usefulness of the WT1 Peptide Vaccine}

The identification of WT1 CTL epitopes was first reported in 2000, followed by the accumulation of successful clinical studies which showed indisputable evidence for the therapeutic potential of the WT1 peptide vaccine. Furthermore, it can currently be expected that, when patients with certain types of hematological malignancies in CR but at high risk of relapse are treated with the WT1 peptide vaccine, they can attain long-lasting relapse-free survival, which may lead to a cure, with minimal side effects $[25,27$, $30-32,35]$. The results of studies performed so far have made it possible to make several proposals that may allow the WT1 peptide vaccine to exert its maximum beneficial action (table 1).

First, the vaccination of patients with MRD should be an important strategy for the vaccine to show its maximum effect $[25,27$, 30-32, 35]. AML patients in CR but at high risk of relapse after chemotherapy are good candidates for this situation [31, 32, 35]. Patients with aggressive hematological malignancies such as acute leukemia who have received allo-HSCT but still have MRD are also good candidates for use of the vaccine to its maximum effect [25, 27, 35]. Of note, patients with ALL, as well as those with AML, who underwent WT1 peptide vaccine therapy in CR after allo-HSCT showed long-term survival [25-27], which suggests that ALL cells are also sensitive to WT1 peptide vaccination.

Second, patients with MDS may be suitable candidates for WT1 peptide vaccine therapy, even if it is not MRD but in relatively advanced stages, provided that substantial normal hematopoiesis remains and disease progression is not too rapid. A series of WT1 
peptide vaccine clinical studies targeting MDS showed clinical responses and/or usefulness such as reduction in tumor burden and improvement in anemia that might be associated with recovery of normal hematopoiesis as a result of the reduction in the abnormal counterpart. A study reported by Keilholz et al. [18] already referred to in this article showed an interesting case of secondary AML from MDS. WT1 vaccination led to a reduction in trisomy 8 clones from 44\%, a high MDS clone burden, to undetectable levels, which was associated with improvement of anemia. Yasukawa et al. [20] also reported a similar MDS case with an improvement in anemia after the vaccination. A vaccination-associated major neutrophil response in 2 patients with high-risk MDS was also shown in Keilholz et al.'s [18] report. Recently, preliminary results of an ongoing clinical trial of WT1 peptide vaccination in patients with MDS after azacitidine failure was reported [36].

Third, the composition of the WT1 peptide vaccine itself is a subject worth considering for the enhancement of its efficacy. So far, most WT1-targeting clinical studies were performed with WT1 CTL peptide-based vaccinations. Following the identification of the CTL epitopes, WT1 helper epitopes were also identified. For example, WT1-332, a 16-mer helper peptide, showed helper activity to enhance WT1-specific CTL induction in vitro [37]. Furthermore, direct recognition and lysis of leukemia cells by WT1-specific CD $4^{+}$ $\mathrm{T}$ lymphocytes were also reported [38]. Very recently, a phase I study of the OCV-501 peptide vaccine (WT1-332 helper peptide) for AML patients in CR showed that the s.c. vaccination was safe and well tolerated [39]. Here, a reduction in WT1 mRNA levels after the vaccination was observed in several patients. According to these findings, a vaccine composed of WT1 CTL and helper peptides is expected to be more powerful than either agent alone. In fact, in the reports already referred to, Maslak et al. [30] used a helper peptide that also includes a CTL epitope, and Miyakoshi et al. [36] used a novel WT1-based peptide vaccine which induces CTLs and also includes a WT1-derived helper peptide. In addition, the development of a more appropriate immune adjuvant will be important and useful for the enhancement of the vaccine's efficacy.

Finally, the combination of WT1 peptide vaccine therapy with other treatment modalities is interesting. We already referred to WT1 peptide vaccination after allo-HSCT $[25,27]$. The post-alloHSCT period presents an MRD condition favorable for vaccine therapy. In addition, since allo-HSCT is an immunotherapy target- ing allo-antigens expressed on leukemia cells, WT1 peptide vaccination after allo-HSCT is a double immunotherapy that targets allo-antigens and the WT1 tumor antigen. In this context, it is interesting that WT1 itself, as well as allo-antigens, seems to be a target antigen of the donor-derived $\mathrm{T}$ lymphocytes [40]. Another combined therapy whose usefulness was suggested in the literature is the addition of WT1 peptide vaccine therapy in CML patients who have MRD and are treated with TKI $[23,24]$. In addition, recently featured topics prompt us to mention checkpoint inhibitors, which constitute a newly emerging cancer immunotherapy, although their action is not tumor-specific and therefore associated with immune-related systemic side effects. Evidence of the efficacy of checkpoint inhibitors for certain types of solid cancers has already been established. If their clinical effectiveness for a variety of hematological malignancies is shown in the future [41, 42], the combined therapy of WT1 peptide vaccination, a tumor antigenspecific immunotherapy, and a checkpoint inhibitor that inhibits tumor immune evasion and broadly activates the immune system should be of considerable interest.

Not only clinical but also basic research-related data, such as those about clonality or gene expression profiles of WT1-specific CTLs, have been accumulated with the analysis of blood samples obtained from previous clinical studies [32, 43, 44], that is, reverse translational research. Blood samples obtained from ongoing and future clinical studies, including those proposed here, should further contribute to accumulating valuable findings about cancer immunology at the cellular and molecular level. Then, based on these novel findings, further enhancement of the efficacy of WT1-targeting cancer immunotherapy is expected.

\section{Online Supplementary Table}

Supplementary table. WT1 peptide vaccine clinical studies for hematological malignancies with positive clinical impact

To access the online supplementary table, please refer to www.karger. $\mathrm{com} / ? \mathrm{DOI}=481353$.

\section{Disclosure Statement}

The authors declare no conflict of interest.

\section{References}

1 Oka Y, Tsuboi A, Oji Y, Kawase I, Sugiyama H: WT1 peptide vaccine for the treatment of cancer. Curr Opin Immunol 2008;20:211-220.

2 Ogawa H, Tamaki H, Ikegame K, Soma T, Kawakami M, Tsuboi A, Kim EH, Hosen N, Murakami M, Fujioka T, Masuda T, Taniguchi Y, Nishida S, Oji Y, Oka Y, Sugiyama H: The usefulness of monitoring WT1 gene transcripts for the prediction and management of relapse following allogeneic stem cell transplantation in acute type leukemia. Blood 2003;101:1698-1704.
3 Cilloni D, Renneville A, Hermitte F, Hills RK, Daly S, Jovanovic JV, Gottardi E, Fava M, Schnittger S, Weiss T, Izzo B, Nomdedeu J, van der Heijden A, van der Reijden BA, Jansen JH, van der Velden VH, Ommen H, Preudhomme C, Saglio G, Grimwade D: Real-time quantitative polymerase chain reaction detection of minimal residual disease by standardized WT1 assay to enhance risk stratification in acute myeloid leukemia: a European LeukemiaNet study. J Clin Oncol 2009;27; 5195-5201.
4 Oka Y, Tsuboi A, Nakajima H, Fujiki F, Nishida S, Morimoto S, Nakata J, Nakae Y, Takashima S, Tatsumi N, Hosen N, Oji Y, Sugiyama H: WT1 peptide vaccine for the treatment of malignancies: its development, recent progress, and future perspectives; in Yamaguchi $\mathrm{Y}$ (ed): Immunotherapy of Cancer. Tokyo, Springer Japan, 2016, pp. 159-185.

5 Cheever MA, Allison JP, Ferris AS, Finn OJ, Hastings BM, Hecht TT, Mellman I, Prindiville SA, Viner JL, Weiner LM, Matrisian LM: The prioritization of cancer antigens: a National Cancer Institute pilot project for the acceleration of translational research. Clin Cancer Res 2009; 15:5323-5237. 
6 Saito Y, Kitamura H, Hijikata A, Tomizawa-Murasawa M, Tanaka S, Takagi S, Uchida N, Suzuki N, Sone A, Najima Y, Ozawa H, Wake A, Taniguchi S, Shultz LD, Ohara O, Ishikawa F: Identification of therapeutic targets for quiescent, chemotherapy-resistant human leukemia stem cells. Sci Transl Med 2010;2:17ra9.

7 Wagner N. Michiels JF, Schedi A, Wagner KD: The Wilms' tumour suppressor WT1 is involved in endothelial cell proliferation and migration: expression in tumour vessels in vivo. Oncogene 2008;27:3662-3672.

8 Oka Y, Elisseeva OA, Tsuboi A, Ogawa H, Tamaki H, Li H, Oji Y, Kim EH, Soma T, Asada M, Ueda K, Maruya E, Saji H, Kishimoto T, Udaka K, Sugiyama H: Human cytotoxic T-lymphocyte responses specific for peptides of the wild-type Wilms' tumor gene (WT1) product. Immunogenetics 2000;51:99-107.

9 Ohminami H, Yasukawa M, Fujita S: HLA class I-restricted lysis of leukemia cells by a CD8+ cytotoxic Tlymphocyte clone specific for WT1 peptide. Blood 2000;95:286-293.

10 Oka Y, Tsuboi A, Fujiki F, Shirakata T, Nishida S, Hosen N, Nakajima H, Li Z, Kawase I, Oji Y, Sugiyama $\mathrm{H}$ : 'Cancer antigen WT1 protein-derived peptide'based treatment of cancer - toward the further development. Curr Med Chem 2008;15:3053-3061.

11 Gao L, Bellantuono I, Elsasser A, Marley SB, Gordon MY, Goldman JM, Stauss HJ: Selective elimination of leukemic CD34+ progenitor cells by cytotoxic T lymphocytes specific for WT1. Blood 2000;95:2198-2203.

12 Oka Y, Udaka K, Tsuboi A, Elisseeva OA, Ogawa H, Aozasa K, Kishimoto T, Sugiyama H: Cancer immunotherapy targeting Wilms' tumor gene WT1 product. J Immunol 2000;164:1873-1880.

13 Tsuboi A, Oka Y, Udaka K, Murakami M, Masuda T, Nakano A, Nakajima H, Yasukawa M, Hiraki A, Oji Y, Kawakami M, Hosen N, Fujioka T, Wu F, Taniguchi Y, Nishida S, Asada M, Ogawa H, Kawase I, Sugiyama H: Enhanced induction of human WT1-specific cytotoxic T lymphocytes with a 9-mer WT1 peptide modified at HLA-A ${ }^{\star 2402-b i n d i n g ~ r e s i d u e s . ~ C a n c e r ~ I m m u n o l ~ I m-~}$ munother 2002;51:614-620.

14 Oka Y, Tsuboi A, Murakami M., Hirai M., Tominaga N., Nakajima H, Elisseeva OA, Masuda T, Nakano A, Kawakami M, Oji Y, Ikegame K, Hosen N, Udaka K, Yasukawa M, Ogawa H, Kawase I, Sugiyama H: Wilms tumor gene peptide-based immunotherapy for patients with overt leukemia from myelodysplastic syndrome (MDS) or MDS with myelofibrosis. Int J Hematol 2003;78:56-61.

15 Mailänder V, Scheibenbogen C, Thiel E, Letsch A, Blau IW, Keilholz U: Complete remission in a patient with recurrent acute myeloid leukemia induced by vaccination with WT1 peptide in the absence of hematological or renal toxicity. Leukemia 2004;18:165-166.

16 Oka Y, Tsuboi A, Taguchi T, Osaki T, Kyo T, Nakajima H, Elisseeva OA, Oji Y, Kawakami M, Ikegame K, Hosen N, Yoshihara S, Wu F, Fujiki F, Murakami M, Masuda T, Nishida S, Shirakata T, Nakatsuka S-I, Sasaki A, Udaka K, Dohy H, Aozasa K, Noguchi S, Kawase I, Sugiyama H: Induction of WT1 (Wilms' tumor gene)-specific cytotoxic T lymphocytes by WT1 peptide vaccine and the resultant cancer regression. Proc Natl Acad Sci USA 2004;101:13885-13890.

17 Rezvani K, Yong ASM, Mielke S, Savini BN, Musse L, Superata J, Jafarpour B, Boss C, Barrett AJ: Leukemiaassociated antigen-specific $\mathrm{T}$-cell responses following combined PR1 and WT1 peptide vaccination in patients with myeloid malignancies. Blood 2008;11:236-242.

18 Keilholz U, Letsch A, Busse A, Asemissen AM, Bauer S, Brau IW, Hofmann W-K, Uharek L, Thiel E, Scheibenbogen C: A clinical and immunologic phase 2 trial of Wilms tumor gene product 1 (WT1) peptide vaccination in patients with AML and MDS. Blood 2009;113:6541-6548
19 Kawakami M, Oka Y, Tsuboi A, Harada Y, Elisseeva OA, Furukawa Y, Tsukaguchi M, Shirakata T, Nishida S, Nakajima H, Morita S, Sakamoto J, Kawase I, Oji Y, Sugiyama $\mathrm{H}$ : Clinical and immunological responses to very low dose vaccination with WT1 peptide $(5 \mu \mathrm{g} /$ body) in a patient with chronic myelomonocytic leukemia. Int J Hematol 2007;85:426-429.

20 Yasukawa M, Fujiwara H, Ochi T, Suemori K, Narumi H, Azuma T, Kuzushima K: Clinical efficacy of WT1 peptide vaccination in patients with acute myelogenous leukemia and myelodysplastic syndrome. Am J Hematol 2009;84:314-315.

21 Van Tendeloo VF, Van de Velde A, Van Driessche A, Cools N, Anguille S, Price DA, Vermeulen K, Pieters K, Nijs G, Stein B, Smits EL, Schroyens WA, Gadisseur AP, Vrelust I, Jorens PG, Goossens H, de Vries IJ, Price DA, Oji Y, Oka Y, Sugiyama H, Berneman ZN: Induction of complete and molecular remissions in acute myeloid leukemia by Wilms' tumor 1 antigentargeted dendritic cell vaccination. Proc Natl Acad Sci USA 2010;107:13824-13829.

22 Tsuboi A, Oka Y, Nakajima H, Fukuda Y, Elisseeva OA, Yoshihara S, Hosen N, Ogata A, Kito K, Fujiki F, Nishida S, Shirakata T, Ohno S, Yasukawa M, Oji Y, Kawakami M, Morita S, Sakamoto J, Udaka K, Kawase I, Sugiyama H: Wilms' tumor gene WT1 peptide-based immunotherapy induced minimal response in a patient with advanced, therapy-resistant multiple myeloma. Int J Hematol 2007;86:414-417.

23 Narita M, Masuko M, Kurasaki T, Kitajima T, Takenouchi S, Saitoh A, Watanabe N, Furukawa T, Toba K, Fuse I, Aizawa Y, Kawakami M, Oka Y, Sugiyama H, Takahashi M: WT1 peptide vaccination in combination with imatinib therapy for a patient with CML in the chronic phase. Int J Med Sci 2010;7:72-81.

24 Oji Y, Oka Y, Nishida S, Tsuboi A, Kawakami M, Shirakata T, Takahashi K, Murao A, Nakajima H, Narita M, Takahashi M, Morita S, Sakamoto J, Tanaka T, Kawase I, Hosen N, Sugiyama H: WT1 vaccine induces reduction in minimal residual disease in an imatinibtreated CML patient. Eur J Hematol 2010;85:358-360.

25 Hashii Y, Sato-Miyashita E, Matsumura R, Kusui S, Yoshida H, Ohta H, Hosen N, Tsuboi A, Oji Y, Oka Y, Sugiyama H, Ozono K: WT1 peptide vaccination following allogeneic stem cell transplantation in pediatric leukemic patients with high risk for relapse: successful maintenance of durable remission. Leukemia 2012;26: 530-532.

26 Sawada A, Inoue M, Kondo O, Yamada-Nakata K, Ishihara T, Kuwae Y, Nishikawa M, Ammori Y, Tsuboi A, Oji Y, Koyama-Sato M, Oka Y, Yasui M, Sugiyama H, Kawa K: Feasibility of cancer immunotherapy with WT1 peptide vaccination for solid and hematological malignancies in children. Pediatr Blood Cancer 2016; 63:234-241.

27 Maeda T, Hosen N, Fukushima K, Tsuboi A, Morimoto S, Matsui T, Sata H, Fujita J, Hasegawa K, Nishida S. Nakata J, Nakae Y, Takashima S, Nakajima H, Fujiki F, Tatsumi N, Kondo T, Hino M, Oji Y, Oka Y, Kanakura Y, Kumanogoh A, Sugiyama H: Maintenance of complete remission after allogeneic stem cell transplantation in leukemia patients treated with Wilms tumor 1 (WT1) peptide vaccine. Blood Cancer J 2013;3:e130.

28 Israyelyan A, Rosa CL, Tsai W, Kaltcheva T, Srivastava T, Aquino L, Li J, Kim Y, Palmer J, Streja L, Senitzer D, Zaia JA, Rosenwald A, Forman SJ, Nakamura R, Diamond DJ: Detection and preliminary characterization of CD8+ T lymphocytes specific for Wilms' tumor antigen in patients with non-Hodgkin lymphoma. Luek Lymphoma 2013;54:2490-2499.
29 Gallo D, Nicoli P, Calabrese C, Gaidano V, Petiti J, Rosso V, Signorino E., Carturan S, Bot-Sartor G, Volpe G, Frassoni F, Saglio G, Cilloni D: The Wilms' tumor (WT1) gene expression correlates with the International Prognostic Scoring System (IPSS) score in patients with myelofibrosis and it is a marker of response to therapy. Cancer Med 2016;5:1650-1653.

30 Maslak PG, Dao T, Krug LM, Chanel S, Korontsvit T, Zakhaleva V, Zhang R, Wolchok JD, Yuan J, PinillaIbarz J, Berman E, Weiss M, Jurcic J, Frattini MG Scheinberg DA: Vaccination with synthetic analog peptide derived from WT1 oncoprotein induces T-cell responses in patients with complete remission from acute myeloid leukemia. Blood 2010;116:171-179.

31 Tsuboi A, Oka Y, Kyo T, Katayama Y, Elisseeva OA, Kawakami M, Nishida S, Morimoto S, Murao A, Nakajima H, Hosen N, Oji Y, Sugiyama H: Long-term WT1 peptide vaccination for patients with minimal residual disease. Leukemia 2012;26:1410-1413.

32 Nakata J, Nakae Y, Kawakami M, Morimoto S, Motooka D, Hosen N, Fujiki F, Nakajima H, Hasegawa K, Nishida S, Tsuboi A, Oji Y, Oka Y, Kumanogoh A, Sugiyama H: Wilms tumor 1 peptide vaccine as a cureoriented post-chemotherapy strategy for patients with acute myeloid leukaemia at high risk of relapse. $\mathrm{Br} \mathrm{J}$ Haematol 2017;Epub ahead of print.

33 Rezvani K, Yong AS, Mielke S, Jafarpour B, Savani BN, Le RQ, Eniafe R, Musse L, Boss C, Kurlander R, Barrett AJ: Repeated PR1 and WT1 peptide vaccination in Montanide-adjuvant fails to induce sustained highavidity, epitope-specific CD8+ T cells in myeloid malignancies. Haematologica 2011;96:432-440.

34 Kuball J, de Boer K, Wagner E, Wattad M, Antunes E, Weeratna RD, Vicari AP, Lotz C, van Dorp S, Hol S Greenberg PD, Heit W, Davis HL, Theobald M: Pitfalls of vaccinations with WT1-, Protainase3- and MUC1derived peptides in combination with Montanide ISA51 and CpG7909. Cancer Immunol Immunother 2011;60:161-171.

35 Oka Y: A vaccine for leukemia: one step closer? Cureoriented WT1 peptide vaccination therapy is being developed. Clin Invest 2013;3:1-4.

36 Miyakoshi S, Usuki K, Matsumura I, Ueda Y, Iwasaki H, Miyamoto T, Origuchi M, Tagashira S, Naoi I, Naoe T, Kizaki M, Heike Y, Akashi K, Miyazaki Y: Preliminary results from a phase $1 / 2$ study of DSP-7888, a novel WT1 peptide-based vaccine, in patients with myelodysplastic syndrome (MDS). Blood 2016;128:4335.

37 Fujiki F, Oka Y, Tsuboi A, Kawakami M, Kawakatsu M, Nakajima H, Elisseeva OA, Harada Y, Ito K, Li Z, Tatsumi N, Sakaguchi N, Fujioka T, Masuda T, Yasukawa M, Udaka K, Kawase I, Oji Y, Sugiyama H: Identification and characterization of a WT1 (Wilms' tumor gene) protein-derived HLA-DRB1*0405-restricted 16-mer helper peptide that promotes the induction and activation of WT1-specific cytotoxic T lymphocytes. J Immunother 2007;30:282-293.

38 Lin Y, Fujiki F, Katsuhara A, Oka Y, Tsuboi A, Aoyama N, Tanii S, Nakajima H, Tatsumi N, Morimoto S, Tamanaka T, Tachino S, Hosen N, Nishida S, Oji Y, Kumanogoh A, Sugiyama H: HLA-DPB1*05:01-restricted WT1332-specific TCR-transduced CD4+ T lymphocytes display a helper activity for WT1-specific CTL induction and a cytotoxicity against leukemia cells. J Immunother 2013;36:159-170.

39 Kobayashi Y, Sakura T, Miyawaki S, Toga K, Sogo S, Heike Y: A new peptide vaccine OCV-501: in vitro pharmacology and phase 1 study in patients with acute myeloid leukemia. Cancer Immunol Immunother 2017;66:851-863. 
40 Revzani K, Yong ASM, Savani BM, Mielke S, Keyvanfar K, Gostick E, Price DA, Douek DC, Barrett AJ Graft-versus-leukemia effects associated with detectable Wilms tumor 1-specific T lymphocytes after allogeneic stem-cell transplantation for acute lymphoblastic leukemia. Blood 2007;110:1924-1932.

41 Ansell SM, Lesokhin AM, Borrello I, Halwani A, Scott EC, Gutierrez M, Schuster SJ, Millenson MM, Cattry D, Freeman GJ, Rodig SJ, Chapuy B, Ligon AH, Zhu L, Grosso JF, Kim SY, Timmerman JM, Shipp MA, Armand P: PD-1 blockade with nivolumab in relapsed or refractory Hodgkin's disease. N Engl J Med 2015;372: 311-319.
42 Gotoh M, Nakamura M, Nakamura M, Suginobe M, Takasu H, Takanashi Y, Ban H, Li CJ: DSP-7888, a novel cocktail design of WT1 peptide vaccine, and its combinational immunotherapy with immune checkpoint-blocking antibody against PD-1. Blood 2016; 128:4715.

43 Ochsenreither S, Fusi A, Busse A, Bauer S, Scheibenbogen $\mathrm{C}$, Stather D, Thiel E, Keilholz U, Letsch A: "Wilms tumor protein 1" (WT1) peptide vaccinationinduced complete remission in a patient with acute myeloid leukemia is accompanied by the emergence of a predominant T-cell clone both in blood and bone marrow. J Immunother 2011;34:85-91.
44 Nakae Y, Oka Y, Fujiki F, Morimoto S, Kamiya T, Takashima S, Nakata J, Nishida S, Nakajima H, Hosen N, Tsuboi A, Kyo T, Oji Y, Mizuguchi K, Kumanogoh A, Sugiyama H: Two distinct effector memory cell populations of WT1 (Wilms' tumor gene 1)-specific cytotoxic $\mathrm{T}$ lymphocytes in acute myeloid leukemia patients. Cancer Immunol Immunother 2015;64:791804 . 